\title{
ソーダ・アルミノ珪酸塩ガラス内の $\mathrm{Eu}^{3+}$ の光学的性質
}

\author{
小見山亭 \\ （大阪工業技術試験所）
}

\section{Optical Properties of $\mathrm{Eu}^{3+}$ in Sodium Aluminosilicate Glass}

\author{
By \\ Tōru KOMIYAMA \\ (Government Industrial Research Institute, Osaka)
}

\begin{abstract}
The optical properties of $\mathrm{Eu}^{3+}$ in the system of $\mathrm{Na}_{2} \mathrm{O} \cdot x \mathrm{Al}_{2} \mathrm{O}_{3} \cdot 2 \mathrm{SiO}_{2}$ glasses were investigated for $x$ values from 0.0 to 1.2 .

The variation of the oscillator strength, intensity ratio, $S\left({ }^{5} D_{0}-{ }^{7} F_{2}\right) / S\left({ }^{5} D_{0}-{ }^{7} F_{1}\right)$, and the broadening of emission line with composition showed a maximum at arround $\mathrm{Al} / \mathrm{Na}$ $=1.0$, while the transition energy of the CTB and the decay time constant of the ${ }^{5} D_{0}$ state showed a minimum at the same ratio. These results suggest that the Eu-O interaction, the assymetry and the variety of sites associated with $\mathrm{Eu}^{3+}$ are the greatest in the vicinity of 1.0 .

The discontinuous changes of the structure-sensitive parameters were discussed with respect to the change of glass structure in terms of the increase of $\mathrm{AlO}_{4}$ tetrahedra and the formation of tri-cluster groups.

The decay time constant showed pronounced decreasing with the increase of $\mathrm{Al} / \mathrm{Na}$ ratio in the composition range $\mathrm{Al} / \mathrm{Na} \leqq 1.0$. It may be regarded from the view point of the estimation of the quantum efficiency of emission from the ${ }^{5} D_{0}$ state that the decrease of the constant are largely attributed to the increase of the radiative transition probability due to the increase of coupling of $\mathrm{Eu}^{3+}$ with the surrounding.
\end{abstract}

[Received July 12, 1974]

\section{1. 緒 言}

ガラス内の稀土類イオンの光学的性質は, 組成あるい は結晶化などによる母体の構造変化に敏感に対応す る ${ }^{1) ~ 6)}$ • たとえば, $\mathrm{Na}_{2} \mathrm{O}-\mathrm{B}_{2} \mathrm{O}_{3}$ 系ガラスでは組成によっ て特異な構造変化が起るが, この影響は導入された稀土 類イオンの種々の光学的性質に反映される. すなわち, 発光スペクトルや励起状態 の緩和速度などの変化は, $\mathrm{B}_{2} \mathrm{O}_{3}$ の含有量が $85 \mathrm{~mol} \%$ 付近で, いわゆる硼酸異常 現象とみなされる不連続性を示すが5) 7), この結果につ いてはすでに詳しく考察されている5).

一方, $\mathrm{Na}_{2} \mathrm{O}-\mathrm{Al}_{2} \mathrm{O}_{3}-\mathrm{SiO}_{2}$ 系ガラスも, 硼酸異常現象 に類似のアルミナ異常現象を示すことが, 多くの物性で 観測されている ${ }^{8) ~ 12)}$. また, 最近 Galant ら ${ }^{13)}$ は, 0.4 mol\%の $\mathrm{Nd}^{3+}$ を含む $13 \mathrm{Na}_{2} \mathrm{O} \cdot x \mathrm{Al}_{2} \mathrm{O}_{3} \cdot(87-x) \mathrm{SiO}_{2}$ ガラスについて, $\mathrm{Nd}^{3+}$ の発光特性にもアルミナ異常現 象が認められるといら結果を報告した.しかし, Galant らの報告では, 発光スペクトルに関する二, 三のパラメ 一タが主な対象となっているにすぎず, ソーダ・アルミ ノ珪酸塩ガラスにおける稀土類イオンの光学的性質と母
体の構造変化の関係は, 必ずしも明らかではない.

この報告は, 一連のガラス内の稀土類イオンの光学的 性質に関する研究 ${ }^{2,3), 7)}$ の一部として, まだ不明の点が 残されているソーダ・アルミノ珪酸塩ガラスの場合につ いて検討したものである. すなわち, 代表的な稀土類イ オンとして, 遷移の性格や母体組成依存性がよく知られ ている $\mathrm{Eu}^{3+}$ を選び, 吸収, 励起, 発光の各スペクトル および励起状態の緩和などに関する広範なパラメータに 基づいて,この系のガラスにおける光学的性質の変化あ るいは特徴を論じた。

\section{2. 実験}

試料は通常の方法により $10 \times 10 \times 15 \mathrm{~mm}$ の大きさの ものを作成した.なお,母体組成は $\mathrm{Na}_{2} \mathrm{O} \cdot x \mathrm{Al}_{2} \mathrm{O}_{3} \cdot 2 \mathrm{SiO}_{2}$ $(x=0.0 \sim 1.2)$ であるが, このガラスの熔融および熱処 理条件については, 倖井らの報告に詳しい ${ }^{12)}$.

$\mathrm{Eu}^{3+}$ は, $\mathrm{Eu}_{2} \mathrm{O}_{3}$ として $0.5 \mathrm{~mol} \%$ の割合になるよ らに添加したが，この濃度では $\mathrm{Eu}^{3+}$ 間の相互作用は無 視することができる。 
33 小見山 亨

各種の光学的性質の測定法は，既報に述べた ${ }^{2), 7) . ~}$

\section{3. 結果}

図-1に，可視域における吸収スペクトルの代表的な 例として, $\mathrm{Al} / \mathrm{Na}$ 比が 0.5 (実線) と 1.0 (点線) の場 合を示す．これについて，母体組成によるピーク位置の シフトは明確でなかったが，吸収線の分裂の様子や吸収 強度は，組成によって異なることが認められた．たとえ ば, $21300 \mathrm{~cm}^{-1}$ および $18500 \mathrm{~cm}^{-1}$ 付近の吸収につい て, $\mathrm{Al}_{2} \mathrm{O}_{3}$ の含有量が多いほど分裂が不明瞭になること がわかる. また，表-1に ${ }^{7} F_{0}$ 準位からの吸収遷移に対 する振動子強度の值を示すが, $\mathrm{Al} / \mathrm{Na}$ 比が増すにつれ て増大し, $\mathrm{Al} / \mathrm{Na}=1.0$ 付近で最大值を示すといら傾向 が認められる.つまり, $\mathrm{Eu}^{3+}$ の吸収強度の変化には, アルミナ異常現象が観測される.一般に, 振動子強度の 増大は, $\mathrm{Eu}^{3+}$ と周囲の結合の増大を意味するとみなさ れるから，この結果は $\mathrm{Eu}^{3+}$ と周囲の相互作用は $\mathrm{Al}_{2} \mathrm{O}_{3}$ の含有量と共に増すが, $\mathrm{Al} / \mathrm{Na}>1.0$ の領域では減少す る傾向があることを示唆している.

図-2に, $\mathrm{Eu}^{3+}$ の ${ }^{5} D_{0}-{ }^{7} F_{2}$ 遷移に対する励起スペク トルの例を示す. $40000 \mathrm{~cm}^{-1}$ 付近のブロードな励起帯 は，母体から $\mathrm{Eu}^{3+}$ への電荷移動に基づくもの（以下， CTB）とみなされるが7)，そのピーク位置は組成により

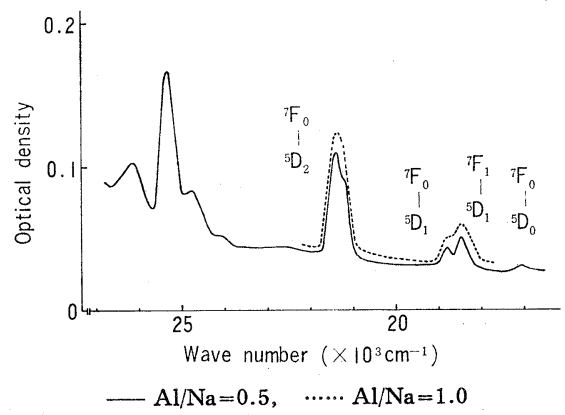

Fig. 1. Absorption spectra of $\mathrm{Eu}^{8+}$ in $\mathrm{Na}_{2} \mathrm{O}$. $x \mathrm{Al}_{2} \mathrm{O}_{3} \cdot 2 \mathrm{SiO}_{2}$ glasses at $\mathrm{RT}$.

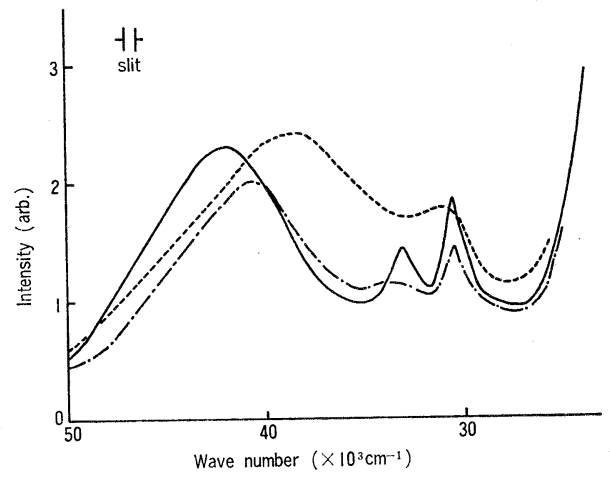

- $\mathrm{Al} / \mathrm{Na}=0.0 \quad-.-\mathrm{Al} / \mathrm{Na}=0.5 \quad \cdots . . . \mathrm{Al} / \mathrm{Na}=1.0$

Fig. 2. Excitation spectra of the ${ }^{5} D_{0}$ emission of $\mathrm{Eu}^{8+}$ in $\mathrm{Na}_{2} \mathrm{O} \cdot x \mathrm{Al}_{2} \mathrm{O}_{3} \cdot 2 \mathrm{SiO}_{2}$ glasses at LNT.
Table 1. Oscillator strength of $\mathrm{Eu}^{3+}$ in $\mathrm{Na}_{2} \mathrm{O}$. $x \mathrm{Al}_{2} \mathrm{O}_{3} \cdot 2 \mathrm{SiO}_{2}$ glasses.

\begin{tabular}{|c|c|c|c|c|c|c|}
\hline \multirow{2}{*}{ Transition } & \multirow{2}{*}{$\begin{array}{l}\text { Wave } \\
\text { number } \\
\left(\mathrm{cm}^{-1}\right)\end{array}$} & \multicolumn{5}{|c|}{$\mathrm{Al} / \mathrm{Na}$} \\
\hline & & 0.3 & 0.5 & 0.7 & 1.0 & 1.2 \\
\hline${ }^{7} F_{0}-{ }^{5} D_{0}$ & 17035 & 0.07 & 0.14 & 0.17 & 0.26 & 0.24 \\
\hline${ }^{7} F_{0}-{ }^{5} D_{1}$ & 18815 & 0.34 & 0.37 & 0.63 & 1.03 & 0.83 \\
\hline${ }^{7} F_{0}-{ }^{5} D_{2}$ & 21365 & 3.74 & 3.92 & 4.15 & 4.76 & 4.57 \\
\hline
\end{tabular}

異なっている. すなわち, ピーク位置を $\mathrm{Al} / \mathrm{Na}$ 比に対 して表わす時, 明らかに $\mathrm{Al} / \mathrm{Na}$ 比の増加と共に CTB は低エネルギー側ヘシフトし，1.0 付近で遷移エネルギ 一が最小になることが認められる（アルミナ異常現象， 図-3).このことは, $\mathrm{Al}_{2} \mathrm{O}_{3}$ の導入によって, $\mathrm{Eu}^{3+}$ とこ れに隣接する酸素イオンの間における電子軌道の重なり が増すことを意味しておうり ${ }^{21)}$ ，上述したことと同様の示 唆を与えている.

図-4 に, 液体空素温度における発光スペクトルの代 表的な例を示す。 まず, ${ }^{5} D_{0}-{ }^{7} F_{2}$ 遷移による発輝線は 結晶場の Stark 効果により最大 5 本に分裂するはずで あるが，その様子は $\mathrm{Al}_{2} \mathrm{O}_{3}$ を含むガラスでは明確でな

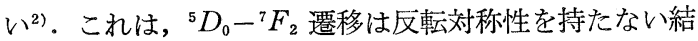
晶場内において電気双極子により許される遷移であり, 結晶場の対称性の変化に敏感であるためである ${ }^{14)}$. 換言 すれば，ソーダ・アルミノ珪酸塩ガラスでは， $\mathrm{Eu}^{3+} の$

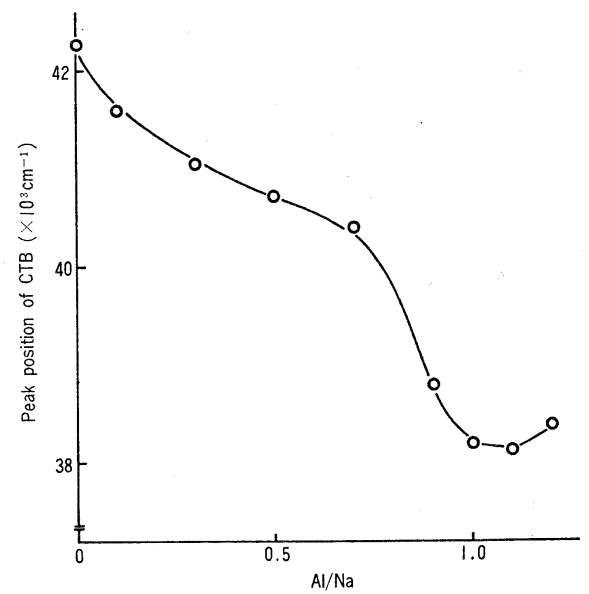

Fig. 3. Variation of the peak position of CTB with $\mathrm{Al} / \mathrm{Na}$ ratio.

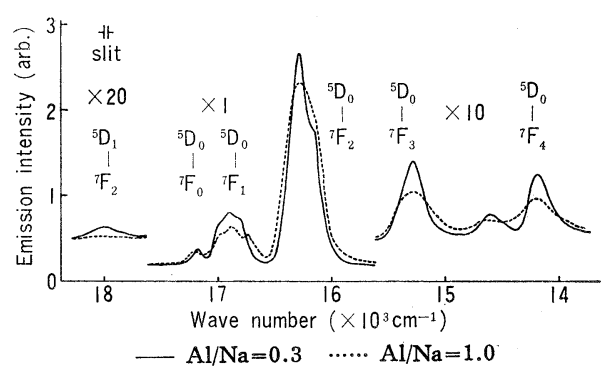

Fig. 4. Emission spectra of $\mathrm{Eu}^{8+}$ in $\mathrm{Na}_{2} \mathrm{O} \cdot x \mathrm{Al}_{2} \mathrm{O}_{3}$. $2 \mathrm{SiO}_{2}$ glasses at LNT. 
周囲の対称性が低いことを意味している，そこで，この 問題についての知見を得るために，周囲の対称性に関す る尺度とみなされる ${ }^{5} D_{0}-{ }^{7} F_{1}$ 遷移の発光強度に対する ${ }^{5} D_{0}-{ }^{7} F_{2}$ 遷移の発光強度の比 ${ }^{15)}$ を求めた. $\mathrm{Al} / \mathrm{Na}$ 比に 対する強度比の変化を図 -5 に示す. 基礎ガラス $\left(\mathrm{Na}_{2} \mathrm{O}\right.$. $\left.2 \mathrm{SiO}_{2}\right) に \mathrm{Al}_{2} \mathrm{O}_{3}$ を導入して行く時, 周囲の対称性は減 少し $\mathrm{Al} / \mathrm{Na}=1.0$ 付近で最も低くなることが示唆され る.これに関連して, 各ガラスについて ${ }^{5} D_{0}-{ }^{7} F_{0}$ 遷移に よる発輝線の半值幅を調べた. 図-6に半值幅と $\mathrm{Al} / \mathrm{Na}$ 比の関係 (○印) を示すが, 比較のために $3 \mathrm{GeO}_{2} \cdot \mathrm{Na}_{2} \mathrm{O}$ ( $\triangle$ 印) および $4 \mathrm{~B}_{2} \mathrm{O}_{3} \cdot \mathrm{Na}_{2} \mathrm{O}$ (×印) ガラスの值 ${ }^{2)}$ も記 した. 図から，ソーダ・アルミノ珪酸塩ガラスではゲル マン酸塩や硼酸塩ガラスよりも半值幅が大きくなる場合 があり, 概して $\mathrm{Eu}^{3+}$ の周囲の均一性は低いといえる. また, 半值幅の $\mathrm{Al} / \mathrm{Na}$ 比依存性は強度比の場合に類似

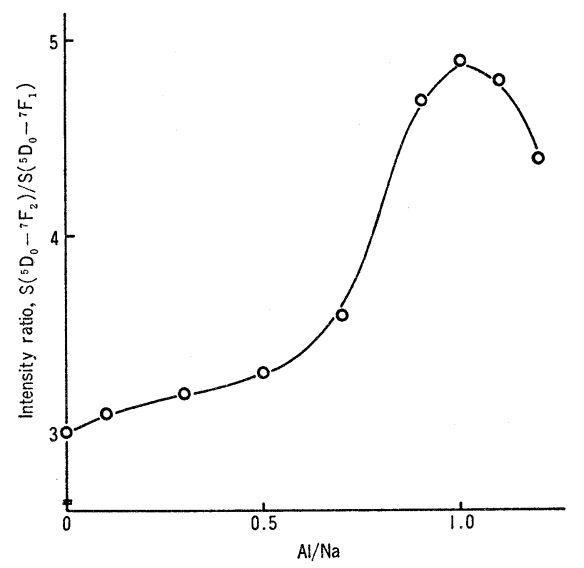

Fig. 5. Variation of the intensity ratio, $S\left({ }^{5} D_{0}-\right.$ $\left.{ }^{7} F_{2}\right) / S\left({ }^{5} D_{0}-{ }^{7} F_{1}\right)$, with $\mathrm{Al} / \mathrm{Na}$ ratio.

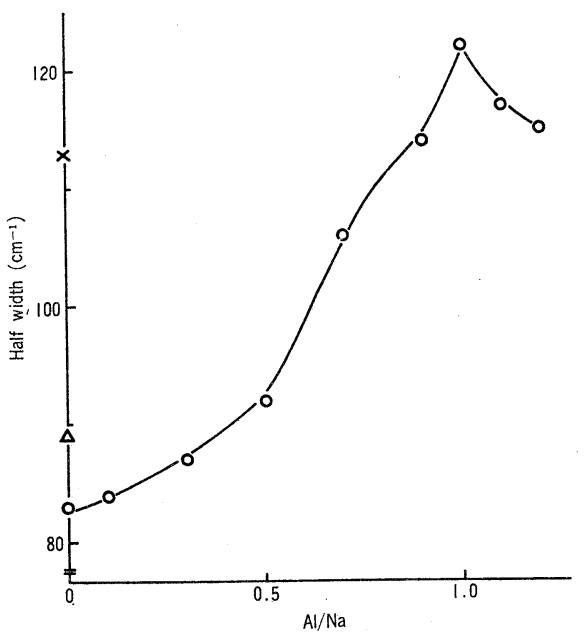

O; $\mathrm{Na}_{2} \mathrm{O} \cdot x \mathrm{Al}_{2} \mathrm{O}_{3} \cdot 2 \mathrm{SiO}_{2} \quad \triangle ; 3 \mathrm{GeO}_{2} \cdot \mathrm{Na}_{2} \mathrm{O}$ $X ; 4 \mathrm{~B}_{2} \mathrm{O}_{3} \cdot \mathrm{Na}_{2} \mathrm{O}$

Fig. 6. Variation of the half width of emission line for the ${ }^{5} D_{0}-{ }^{7} F_{0}$ transition with $\mathrm{Al} / \mathrm{Na}$ ratio.
しており,やはり $\mathrm{Al} / \mathrm{Na}=1.0$ 付近で最大值を示す. し たがって, 周囲の均一性もこの組成点で最も低くなるこ とが示唆される。

${ }^{5} D_{1}-{ }^{7} F_{j}$ 遷移の発光強度は, ${ }^{5} D_{0}-{ }^{7} F_{j}$ 遷移の強度に 比較して著しく弱い（図-4）が, 両者の強度比は母体組 成によって異なる.すなわち, 図-4に示した発輝線は ${ }^{5} D_{1}-{ }^{7} F_{2}$ 遷移に相当するが，この発光強度を ${ }^{5} D_{0}-{ }^{7} F_{0}$ 遷移の強度に対する比として表わす時, $\mathrm{Al} / \mathrm{Na}$ 比が $0.0,0.3,0.7$ の場合，それぞれ約 $0.20,0.15,0.06$ であり，Al/Na>0.7 のガラスでは ${ }^{5} D_{1}-{ }^{7} F_{2}$ 遷移は検 出できない(図-4). なお, Reisfeld らによれば16),17), 燐酸塩およびゲルマン酸塩ガラスにおけるこの值は，そ れぞれ約 $0.18,0.25$ であり，ソーダ・アルミノ珪酸塩 ガラスに比較して大きいことが示されている.このこと は, $\mathrm{Al}_{2} \mathrm{O}_{3}$ を含むガラスでは $\mathrm{Eu}^{3+}$ と周囲の結合が比較 的強く, ${ }^{5} D_{1}$ 準位における multiphonon relaxation の 確率が増すためと考えられる ${ }^{17)}$.

図-7に, ${ }^{5} D_{0}$ 準位の減衰時定数 (以下, $\tau$ ) と $\mathrm{Al} / \mathrm{Na}$ 比の関倸を示すが, $\tau$ の変化にはやはり $\mathrm{Al} / \mathrm{Na}=1.0$ 付 近で最小值が認められ, アルミナ異常現象が観測され る.この結果も, $\mathrm{Eu}^{3+}$ と周囲の相互作用の増大（ある いは, $\mathrm{Al} / \mathrm{Na}>1.0$ の領域では減少)に帰せられる. な お， $\mathrm{Al} / \mathrm{Na}<1.0$ の領域における $\tau$ の顕著な変化に対 する輻射および無輻射遷移の寄与については, 次節で述 ベる.

\section{4. 考察}

\section{$4.1 \mathbf{E u}^{3+}$ の存在状態と母体組成の関係}

ソーダ・アルミノ珪酸塩ガラスに現われるアルミナ異 常現象について，これまで Al 原子の酸素配位数変化に 基づく説明が，多くの研究者によって提案されてき $た^{8), 9)}$. Galant らも, $\mathrm{Nd}^{3+}$ の発光特性で観測されるア ルミナ異常現象を，この考え方で解釈した ${ }^{13)}$.しかし，

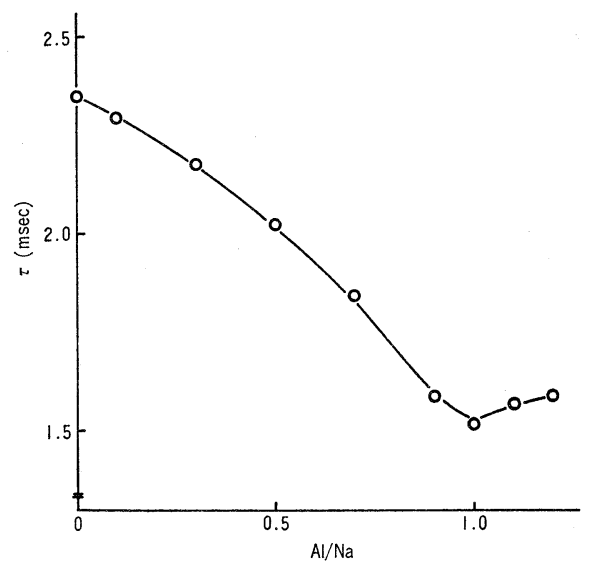

Fig. 7. Variation of the decay time constant for the ${ }^{5} D_{0}$ state with $\mathrm{Al} / \mathrm{Na}$ ratio. 
35 小見山 亭

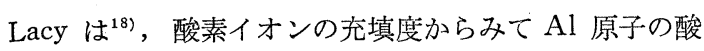
素配位数が 6 である可能性は少ないことを示し, $\mathrm{Al} / \mathrm{Na}$ $>1.0$ の領域では, $\left[\mathrm{SiO}_{4}\right]$ と $\left[\mathrm{AlO}_{4}\right]$ から成る tricluster 構造が形成されると主張した。この提案は, Heckman らによって支持されたが ${ }^{19)}$ ，さらに寺井ら ${ }^{20)}$ は, 蛍光X線による $\mathrm{Al} \mathrm{K} \alpha$ ピークの化学シフトを測定 し,これに対する一つの根拠を与えた.すなわち, $\mathrm{Na}_{2} \mathrm{O}$ ・ $x \mathrm{Al}_{2} \mathrm{O}_{3} \cdot 2 \mathrm{SiO}_{2}$ ガラスでは, $x$ が $0.1 \sim 1.2$ の範囲で $\mathrm{Al}$ $\mathrm{K}_{\alpha}$ ピークのシフトは認められず，したがって $\mathrm{Al}$ 原子 は常に酸素 4 配位をとると結論した. そこで, この報告 では, 前節で示した $\mathrm{Eu}^{3+}$ の光学的性質に現われるアル ミナ異常現象を, 後者の提案に基づいて説明することを 試みた.

まず，基礎ガラスに $\mathrm{Al}_{2} \mathrm{O}_{3}$ を導入して行く時，これ らは $\left[\mathrm{AlO}_{4}\right]$ として $\left[\mathrm{SiO}_{4}\right]$ と共にガラス網目の形成に 参加し, 構造の充填度を増すことが示されている(2),18). しかるに, $\mathrm{Eu}^{3+}$ は隣接する $\mathrm{O}^{2-}$ との間に相互作用をす るが，構造の緻密化は $\mathrm{Eu}-\mathrm{O}$ 間距離の減少をもたらし， 相互作用の増大を結果すると考えられる. $\mathrm{Al} / \mathrm{Na}<1.0$ の領域において， $\mathrm{Al} / \mathrm{Na}$ 比と共に相互作用が増すとい ら示唆は, 主としてこの理由によると思われる.これに 対し, $\mathrm{Al} / \mathrm{Na}>1.0$ の領域では, 構造の充填度がさらに 増すにも拘わらず，わずかながら相互作用は減少すると いら示晙が与えられた, このことは, $\left[\mathrm{AlO}_{4}\right]$ の増加あ るいは tri-cluster の形成によって非架橋酸素イオンが 消滅することに基因すると考えられる. すなわち, $\mathrm{Eu}^{3+}$ に対する電場の影響は, 非架橋酸素イオンよりも架橋酸 素イオンの方が小さいとみなされるからである。

一方, $\mathrm{Al} / \mathrm{Na}$ 比の増加に伴なら周囲の対称性と均一 性の低下は, $\mathrm{Eu}^{3+}$ に対して $\left[\mathrm{SiO}_{4}\right]$ と $\left[\mathrm{AlO}_{4}\right]$ の 2 種 類の配位子が形成されることによると考えられる.この ことは, $\mathrm{Eu}^{3+}$ を含む硼酸塩ガラスにおいて, $\left[\mathrm{BO}_{4}\right]$ が 形成されるにつれて周囲の対称性や均一性が低下すると いう結果に対応するといえる ${ }^{5)}$. 以上は $\mathrm{Al} / \mathrm{Na}<1.0$ の 領域についてであるが, 明らかに $\mathrm{Al} / \mathrm{Na}>1.0$ の領域 では逆の傾向, すなわち $\mathrm{Al} / \mathrm{Na}$ 比と共に対称性と均一 性が増すことが示された. Galant ら ${ }^{13)}$ も, $\mathrm{Nd}^{3+}$ の発光 スペクトルの測定に基づいて同様の示唆を与え, $\left[\mathrm{AlO}_{6}\right]$ の生成によると述べたが, $\left[\mathrm{AlO}_{6}\right]$ の存在はさらに配位 子の種類を増し矛盾を生ずる.したがって, $\mathrm{Al} / \mathrm{Na}>1.0$ の領域における対称性や均一性の変化についても, 上述 したように, 非架橋酸素イオンが消滅し構造の規則性が 増すことに関係があると思われる。

\section{$4.2{ }^{5} D_{0}$ 準位の遷移確率}

ソーダ・アルミノ珪酸塩ガラスにおける $\tau$ 值は $\mathrm{Al} / \mathrm{Na}$ 比が $0.1 \sim 1.0$ の範囲で, $2.30 \mathrm{msec}$ から $1.52 \mathrm{msec}$ ま で減少し, その変化量は網目形成酸化物の種類が異なる ガラス間の差に匹敵する. そこで, このような $\tau$ 值の大
窒業協会誌 83 [3] 1975131

きな変化が何によってもたらされるかを検討するため に, ${ }^{5} D_{0}$ 準位の量子効率（以下， $\eta$ ）を見積った.いま， 比較的せまい吸収带については, 輻射遷移確率 $1 / \tau_{0}$ と の間につぎの関係がある.

$$
1 / \tau_{0}=2.88 \times 10^{-9} \cdot n^{2} \cdot\left(g_{l} / g_{u}\right) \cdot \nu^{2} \int \varepsilon(\nu) \cdot d \nu
$$

ここで, $n$ は母体の屈折率, $g_{l}$ と $g_{u}$ はそれぞれ励起

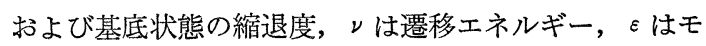
ル吸光係数である. しかるに, ${ }^{5} D_{0}$ 準位の輻射遷移確率 を $1 / \tau_{R}$ とすれば, $\eta$ は $\tau / \tau_{R}$ で表わされるが, Reisfeld らによれば16)， ${ }^{7} F_{0}-{ }^{5} D_{0}$ 遷移による吸収について $1 / \tau_{0}$ を算出し，こ离が ${ }^{5} D_{0}-{ }^{7} F_{0}$ 遷移の輻射遷移確率に等し いと仮定する時, $* 1 / \tau_{R}$ は次式で与えられる.

$$
\begin{aligned}
\frac{1}{\tau_{R}}= & \frac{1}{\tau_{0}}\left[1+\frac{S\left({ }^{5} D_{0}-{ }^{7} F_{1}\right)}{S\left({ }^{5} D_{0}-{ }^{7} F_{0}\right)}+\frac{S\left({ }^{5} D_{0}-{ }^{7} F_{2}\right)}{S\left({ }^{5} D_{0}-{ }^{7} F_{0}\right)}\right. \\
& +\frac{S\left({ }^{5} D_{0}-{ }^{7} F_{3}\right)}{S\left({ }^{5} D_{0}-{ }^{7} F_{0}\right)}+\frac{S\left({ }^{5} D_{0}-{ }^{7} F_{4}\right)}{S\left({ }^{5} D_{0}-{ }^{7} F_{0}\right)} \\
& \left.+\frac{S\left({ }^{5} D_{0}-{ }^{7} F_{5}\right)}{S\left({ }^{5} D_{0}-{ }^{7} F_{0}\right)}+\frac{S\left({ }^{5} D_{0}-{ }^{7} F_{6}\right)}{S\left({ }^{5} D_{0}-{ }^{7} F_{0}\right)}\right] \cdots
\end{aligned}
$$

ここで, $S$ は発輝線の面積で表わした発光強度であ る.そこで, 吸収スペクトルおよび分光感度補正を行っ た発光スペクトルに基づいて $1 / \tau_{R}$ を見積ると， $\mathrm{Al} / \mathrm{Na}$ $=0.3$ のガラスでは $456 \mathrm{sec}^{-1}, 1.0$ の場合には $588 \mathrm{sec}^{-1}$ の值が得られた。したがって，クはそれぞれ 93\%，89\% となり, $\mathrm{Al} / \mathrm{Na}=1.0$ のガラスでは明らかに減少するこ とが認められる.このことは, $\mathrm{Al}_{2} \mathrm{O}_{3}$ の含有量と共に ${ }^{5} D_{0}$ 準位の無輻射遷移確率が増すことを意味している が，その増加は全遷移確率（すなわち $1 / \tau$ ) の増加に比 較してきわめて小さい. すなわち，2つのガラスについ て $1 / \tau$ の差は $165 \mathrm{sec}^{-1}$ であるのに対し. 無輻射遷移確 率の差は $30 \mathrm{sec}^{-1}$ にすぎない. したがって, $\mathrm{Al} / \mathrm{Na}$ 比 の増加に伴なう $\tau$ 值の減少は, 主として $\mathrm{Eu}^{3+}$ と周囲の 結合の増大に基因した輻射遷移確率の増加によるとみな される。

なお， $\mathrm{Eu}^{3+}$ の ${ }^{5} D_{0}$ 準位における無輻射遷移確率が小 さいことは, ${ }^{5} D_{0}$ と ${ }^{7} F_{j}$ 準位間のエネルギー差が大きい (約 $16000 \mathrm{~cm}^{-1}$ 以上) ことに帰せられる. すなわち, ガ ラス網目の振動エネルギーが約 $1200 \mathrm{~cm}^{-1}$ 程度であるこ とを考える時, この準位間でフォノンの放出あるいは結 合を伴った遷移が起るには, 少なくとも 12 ケ以上のフ オノンが必要とみなされるが, 室温付近でこのような過 程が起ることは考えられないからである. 実際, ガラス 内の $\mathrm{Eu}^{3+}$ における ${ }^{5} D_{0}$ 準位の $\eta$ は, 母体組成に関係 なく, 一般に高い值が示されている ${ }^{17)}$.

\section{5. 総 括}

(1) $\mathrm{Eu}^{3+}$ を含む $\mathrm{Na}_{2} \mathrm{O} \cdot x \mathrm{Al}_{2} \mathrm{O}_{3} \cdot 2 \mathrm{SiO}_{2}$ ガラスにつ いて， $x$ を0.0〜1.2の範囲に渉って変化させた場合で 
光学的性質を測定し，母体の構造変化が $\mathrm{Eu}^{3+}$ の挙動に どのような影響を与えるかに関して検討した.

（2） $\mathrm{Eu}^{3+}$ の光学的性質に関する種々のパラメータ の母体組成依存性には, $\mathrm{Al} / \mathrm{Na}=1.0$ 付近で不連続性が 認められた. すなわち, 吸収の振動子強度は最大值を, CTB の遷移エネルギーおよび ${ }^{5} D_{0}$ 準位の $\tau$ は最小值を それぞれ示し，この組成点で $\mathrm{Eu}^{3+}$ と周囲の相互作用は 最も大きいことが示唆された.また ${ }^{5} D_{0}-{ }^{7} F_{2}$ と ${ }^{5} D_{0}-{ }^{7} F_{1}$ 遷移の発光強度比および発輝線の拡がりは同じ組成点で 最大值を示し, 周囲の対称性と均一性は最も低いと述べ られる.これらの結果は, 導入された $\mathrm{Al}_{2} \mathrm{O}_{3}$ が $\left[\mathrm{AlO}_{4}\right]$ としてガラス網目の形成に参加し, $\mathrm{Eu}-\mathrm{O}$ 間距離の減少, 配位子の種類の増加および非架橋酸素イオンの消滅など の効果をもたらすためと考えられた.

（3） $\tau$ 值は， $\mathrm{Al} / \mathrm{Na}$ 比が $0.1 \sim 1.0$ の範囲で 2.30 $\mathrm{msec}$ から $1.52 \mathrm{msec}$ まで, きわめて大きな減少を示し た.しかるに, $\mathrm{Al} / \mathrm{Na}=0.3$ および 1.0 のガラスについ て ${ }^{5} D_{0}$ 準位の $\eta$ を見積る時，その值は $93 \%$ と $89 \%$ で, 全遷移確率の増加に比較して無輻射遷移確率の増加 はきわめて小さいことが認められた。したがって， $\mathrm{Al}$ $\mathrm{Na}$ 比の増加に伴う $\tau$ 值の減少は, 主として $\mathrm{Eu}^{3+}$ と周 囲の結合の増大に基因した輻射遷移確率の増加によると みなされる。

実験に協力頂いた，近畿大学 理工学部学生 香川照文氏に感 謝します。

\section{文献}

1) C.R. Kurkjian et al., Phys. Chem. Glasses 4, 23946 (1963).

2) 小見山 亨, 上野 力, 㸃協 80, 227-32 (1972).

3) 小見山 亨, 他, 工化 72, 839-43 (1969).

4) C. Hirayama, D.W. Lewis, Phys. Chem. Glasses 5, 44-51 (1964).

5) P.K. Gallagher et al., ibid. 6, 95-103 (1965).

6) C. Hirayama, ibid. 7, 52-55 (1966).

7）小見山 亨, 窯協 (印刷中).

8) D.E. Day, G.E. Rindone, J. Amer. Ceram. Soc. 45, 489-96 (1962).

9) J.O. Isard, I. Soc. Glass Tech. 43, $113 \mathrm{~T}-23 \mathrm{~T}$ (1959).

10) D.E. Day, G.E. Rindone, J. Amer. Ceram. Soc. 45 , 496-504 (1962).

11) A.J. Burggraaf, J. Cornelissen, Phys. Chem. Glasses 4, 123-29 (1964).

12) R. Terai, ibid. 10, 146-52 (1969).

13) E.I. Galant et al., Opt. Spectroscopy 31, 142-44 (1971).

14) G. Blasse et al., J. Phys. Chem. Solids 27, 1587-92 (1966).

15) G. Blasse, A. Bril, Philips Res. Rep. 21, 368-78 (1966).

16) R. Reisfeld et al., J. Phys. Chem. 76, 1293-97(1972).

17) R. Reisfeld, N. Lieblich, J. Phys. Chem. Solids 34, 1467-76 (1973).

18) E.D. Lacy, Phys. Chem. Glasses 4, 234-38 (1963).

19) R.W. Heckman et al., ibid. 8, 145-50 (1967).

20）寺井良平, 他, 大工試季報 20, 176 (1969).

21) G. Blasse, J. Chem. Phys. 45, 2356-60 (1966).

(7/12/1974 受付) 